\title{
The Prevalence and Infectivity of Entamoebahistolytica in Baghdad Province
}

\author{
Safa Tawfeeq Waheeb ${ }^{1}$, Braa A. Alshakir ${ }^{2}$, Hasanain Sahib Salih ${ }^{1}$, Faisal Ali Lattef ${ }^{2}$, Rafal Salam Kadhim² \\ ${ }^{1}$ Lecturer,College of Pathological Analysis Techniques/AL-Bayan University Iraq, \\ ${ }^{2}$ Assist. Lecturer,College of Pathological Analysis Techniques/AL-Bayan University Iraq
}

\begin{abstract}
The present study aimed to explore the Entamoebahistolytica in 500 patients (human stool) selected from a private laboratory in Baghdad/Iraq during the period from $1^{\text {st }}$ of April 2018 till the $31^{\text {th }}$ of August, by using the iodine stain to detect the stages of parasite in all samples, evaluate the prevalence of the parasite between males and females and to evaluate the relationship of the parasite in selected months of this study. This study showed that the total number of infected patients is 394 from 500 taken sample. The high incidence (81.13\%) is occurred in August and the low incidence (76.84\%)is occurred in April. This result showed no significant differences appeared between the chosen months of the study $(\mathrm{P}<0.01)$. The result of this study showed no significant differences $(\mathrm{p}<0.01)$ appeared between the males and females of the study, the number of infected patients are (192 males out of 240 and 202 females out of 260).
\end{abstract}

Keywords: Prevalence, infectivity, Entamoebahistolytica, Baghdad province.

\section{Introduction}

Entamoebahistolytica is considered one of the intestinal parasites of the protozoa family which causes severe diarrhea(dysentery) in man. ${ }^{(1,2)}$ Entamoebahistolytica is considered one of the pathogenic parasites and leads to amoebiasis and considered one of the main causes of diarrhea in developing countries, the parasites have two stages to complete their life cycle, an active phase inside the host and an inactive phase there is outside a host. (2)

The World Health Organization has indicated that 3.5 billion people have intestinal parasites and about 450 million suffer from these parasites. ${ }^{(3)}$

The encapsulated phase(cyst stage) is the infected phase that exits with the droppings of the affected human and contains four nuclei and average $20 \mu \mathrm{m}$ in diameter . As for the active phase with a size ranging from 10 to $60 \mu \mathrm{m}$, it is the one present in the large intestine of the host that causes damage to the intestinal wall and the appearance of blood with diarrhea. ${ }^{(4,5)}$

This parasite is transmitted in several ways, the most important of which is taking the cysts through contamination of water and food, through contact with two people, one of which is infected and the other is intact, contact with affected areas and finally swimming in water contaminated with the cysts of the parasite, clinical symptoms differ from one person to another, that is, the appearance of signs depends on the number of parasites present in the host, in simple cases, no symptoms appear, but in severe cases there is pain in the abdomen and bloody diarrhea. ${ }^{(6,7)}$.

There are few reports of confirmed cases of amebiasis in the dog and even less information on amebicides, their dosages and side effects pertaining to animals ${ }^{(8)}$.

\section{Material and Method}

The samples were taken from a private laboratory in Baghdad governorate/Iraq during the $1^{\text {st }}$ of April 2018 till the $31^{\text {th }}$ of August. The number of Stool samples were 500, collected from (males and females) and added inside clean plastic bottles and then detected the stages of parasite by Lugol's Iodine stain.

The preparation of Lugol's Iodine is by Diluted 1:5 with sterile de-ionized water. (This working solution should be prepared fresh approximately every 3 weeks), Prepare a direct smear of the specimen, Place a coverslip over the sample and examine the wet mount preparation 
for the presence of motile protozoa. The organisms are very pale and transparent and are more easily observed under low light intensity, once the wet mount has been thoroughly examined, a drop of Lugol's Iodine (working solution) can be placed at the edge of the coverslip, or a new mount can be prepared using iodine alone; examine the slide for the presence of brown parasitic structures. ${ }^{(9,10,11)}$

\section{Result and Discussion}

This study showed that the total number of infected patients were (394) from 500 samples that had been taken and percentage was $(78.8 \%)$.

The high incidence was $(81.13 \%)$ that appeared in August and the low incidence was (76.84\%) that appeared in April as shown in the Table (1), this result showed a prevalence of parasite in Baghdad and no significant differences between the months during period of this study.

Table 1: Show infection with Entamoebahistolytica according months of study.

\begin{tabular}{|l|c|c|c|}
\hline Months & Total number of exanimated patients & Number of positive (+) patients & Percentage \% \\
\hline April & 95 & 73 & $76.84 \%$ \\
\hline May & 103 & 80 & $77.66 \%$ \\
\hline June & 97 & 77 & $79.38 \%$ \\
\hline July & 99 & 78 & $78.78 \%$ \\
\hline August & 106 & 86 & $81.13 \%$ \\
\hline Total & $\mathbf{5 0 0}$ & $\mathbf{3 9 4}$ & $\mathbf{7 8 . 8 \%}$ \\
\hline
\end{tabular}

This study showed that the total number of infected patients were (192 males and 202 females) from 500 samples that had been taken and percentage was (78.8\%).
The incidence was (80\%)in males and (77.69\%) in females, that appeared in the Table (2), this result revealed no significant differences between the gender during period of this study $(\mathrm{p}<0.01)$.

Table (2): Show the percentage of males and females infected person

\begin{tabular}{|l|c|c|c|c|c|c|}
\hline Number of total examined & \multicolumn{4}{|c|}{ Samples infected } & \multicolumn{3}{c|}{ Total } \\
\hline Method of examination & Male & Female & Male & Female & Male & Female \\
\hline Iodine stain & 240 & 260 & 192 & 202 & $80 \%$ & $77.69 \%$ \\
\hline
\end{tabular}

The reason of the absence of significant differences $(p<0.01)$ between months in this results it's due to exposure the patients to the bad environment and low hygiene as well as food and water contamination with cyst of Entamoebahistolytica.

This research appeared that Entamoebahistolytica increased of incidence in hot months (from April to August), that agreed with. ${ }^{(12,13,14,15,16)}$
The cyst stage of Entamoebahistolytica was more active during hot months; our results agreed with. ${ }^{(17,18)}$

The incidence of this disease in hot months (from April to August) was without any significant variation as a result of the infected stage (cyst) of Entamoebahistolytica staying for weeks and resistance of the bad environment without destroyed the cyst besides the sample taken from symptomatic patients within the high temperature 
months and this condition considered good environment to survive the cyst, this study agreed with. ${ }^{(5,6,13)}$

The reason of the absence of significant differences $(p<0.01)$ between gender in this results it's due to exposure both the gender to the same bad environment and low hygiene as well as food and water contamination with cyst of Entamoebahistolytica.

This study was disagree with other studies that recorded not important higher differences in proportions of infection between females and males in Baghdad (19) and Mosul city ${ }^{(20)}$.

The reason for the different incidence of infection between males and females is attributed to the difference between body structure, immunity and addition to the physiology of the body for both genders, e.g. endocrine activity as male bodies are more tolerant than those of females $^{(21)}$.

Financial Disclosure: There is no financial
disclosure.

Conflict of Interest: None to declare.

Ethical Clearance: All experimental protocols were approved under the College of Pathological Analysis Techniques and all experiments were carried out in accordance with approved guidelines.

\section{References}

1. Guerrant RL. Amebiasis: introduction, current status, and research questions. Rev. Infect. Dis. 1986; 8:218-227.

2. Ryan KJ, Ray CG.Sherris Medical Microbiology. 4th Edition, McGraw Hill, New York.2004; 733778.

3. WHO. Intestinal Parasites.http://apps.who.int/ctd/ intpara/burdens.htm.2010.

4. Walsh JA. Problems in recognition and diagnosis of amebiasis: estimation of the global magnitude of morbidity and mortality. Rev. Infect. Dis. 1986; 8:228-238.

5. Escolà-Vergé, L, Arando M, Vall M,Rovira, Roger; Espasa, Mateu; Sulleiro, Elena; Armengol, Pere; Zarzuela, Francesc; Barberá, María-Jesús.2017.

6. Caler E, Lorenzi H. Entamoebahistolytica: Genome Status and Web Resources". Anaerobic Parasitic
Protozoa: Genomics and Molecular Biology. 2010.

7. Kucik CJ, Martin GL, Sortor BV. Common intestinal parasites". American Family Physician.2004; 69 (5): 1161-8.

8. NORTHWAY RB. Entamoebahistolytica in a dog. Vet. Med. small Anim. Clin. 1975; 70: 306.

9. Layla Ben Ayed National Institute of Agronomy, Tunis Tunis, Tunisia; Sonia SabbahiInstitut National de Recherche en Génia Rural, Eaux et Forêts Tunis, Tunisia.

10. Garcia LS, Bruckner DA. Diagnostic medical parasitology. New York: Elsevier, 1988.

11. Forbes BA, Sahm DF, Weissfeld AS. Bailey and Scott's diagnostic microbiology. 10th ed. St. Louis: Mosby, 1998.

12. Murray PR, Baron EJ, Pfaller MA, Tenover FC, Yolken RH. Manual of clinical microbiology. 7th ed. Washington: ASM, 1999.

13. Ayoub A, Ouhood M, Raghad H. Prevalence of Two Gastrointestinal Parasites Entamoebahistolytica and Giardia lambliawithin Samarra City, Iraq, Advances in Bioscience and Biotechnology. 2017; 8: 399-410.

14. Kurt O, Demirel M, Ostan I. Investigation of the Prevalence of Amoebiasis in Izmir Province and Determination of Entamoeba Species using PCR and Enzyme Mmunoassay. New Microbiology. 2008; 31: 393-400.

15. Nassir A. Diagnostic Epidemiologic Study of Some Species of Entamoebar using PCR in Tikrit. MSc Thesis, Faculty of Sciences, University of Tikrit. 2010.

16. Jaaffer H. Prevalence of Gairdialamblia and Entamoeba histolytic/Entamoebadispar Infections among Children in AL-Shulaa and AL-khadimyaBaghdad-Iraq. Journal of University of Anbar for Pure Science. 2011; 5: 6-10.

17. Al-Musawi K, Al-Yazi W. Studies on Parasitic Diarrhea Causes in Children at Karbala City. Scientific Journal of Karabla University. 2006; 4: 17-30.

18. Bazzaz A, Ahmad N. Prevalence of Some Parasitic Infectious Diseases within Kerkuk City for Years 2009-2014. European Journal of Pharmaceutical and Medical Research. 2016; 3: 13-19. 
19. Jaaffer H. Prevalence of Gairdialamblia and Entamoeba histolytic/Entamoebadispar Infections among Children in AL-Shulaa and AL-khadimyaBaghdad-Iraq. Journal of University of Anbar for Pure Science. 2011; 5: 6-10.

20. Fattuhi Z, Hussein S, Mahfudh, N. Studies of Diarrhea Causing Intestinal Parasites and Some
Effects in Children at Naynawa City. Scientific Rafidain Journal. 2008; 19: 37-50.

21. Zahida T,Shabana K, Lashari MH. Prevalence of Entamoebahistolyticain Humans. Pakistani Journal of Pharmceutical Science. 2010; 23: 344-348. 